\title{
A Look into Jewish Aesthetics and Abstraction
}

\author{
Leah Brand \\ University of Florida
}

Faculty mentor: Rachel Silveri, School of Art \& Art History

\begin{abstract}
Responding to art critic Harold Rosenberg's notions of the state of, and even existence of Jewish art in the mid-twentieth century, this paper questions the relationship of identity and artistic practice, and contends with Rosenberg's points of argument, looking at artists and art practices that could answer to Rosenberg's questioning and eventually focusing on the creative process and theory of Ashkenazi artist Mark Rothko. Keywords: Jewish art, Abstract Expressionism, Harold Rosenberg, Mark Rothko
\end{abstract}

\section{Is There a Jewish Art?}

On July $1^{\text {st }} 1966$, Commentary Magazine published an article by art critic Harold Rosenberg based on a talk he gave at The Jewish Museum some months prior, that asked a single question: "is there a Jewish art?" (Rosenburg, Harold 1966). If a "goy,” a non-Jewish person, were asked, "Is there a Jewish art?" Rosenberg predicts their answer to be either "yes" or "no," however, ask a Jewish person and they will counter, "What do you mean by Jewish art?" Rosenberg acknowledges that Jewish culture turns on the axis of questioning. He attempts to name possibilities for what one might mean when referring to Jewish art. One could be alluding to ceremonial objects, like some of the pieces which would have been presented at the Jewish Museum during the time that Rosenberg would have given his talk, which exist in a purgatory between ceremonial articles and art objects. But these objects are rarely considered in the same sphere of art as the works favored by the canon. The ceremonial objects are art in that they are valued for their relevancy in an established culture. The implications of considering these as Jewish art are similar to the way that "ethnic arts and crafts" are otherized, exoticized and mystified by western culture. It invokes anti-Semitic rhetoric through the hierarchical dismissal of these forms of art as "lesser" than the cultural objects produced by the Nazi-privileged Aryan race and echo the notions popularized by the Nazi party not too long before this talk was initially given; that Jews are incapable of creating "high" art, or any art at all. If we are to search for 
Jewish art in the modern and contemporary understanding of "art", which lifts up and champions Jewish creation, Rosenberg suggests that art made by Jewish people or art that depicts Jewish subjects could be Jewish art. The artist Marc Chagall might fit these definitions, as he and his work are referenced in Rosenberg's talk, yet there remains some uncertainty as to what qualifies a "Jewish theme" and if Chagall succeeds at depicting any of them.

Chagall rarely waned from his characteristic use of non-local color and overt references to the Torah. In his painting, Moses Receiving the Tablets of the Law, (c. 1952, fig. 1) Moses, green in visage, with a billowing gown of blacks, greys, and whites, reaches up to the heaven to receive the Ten Commandments as the Israelites look on from afar with the tablets revealing Hebrew characters. Hebrew, a language that is intrinsically associated with Jewish identity and religion, is very prominent in the composition. However, attempting to categorize Jewish art with the same methodology that one would look to identify Christian art is bound to be muddy. The Judeo-Christian likeness starts and ends with shared characters and a monotheistic resolve. The more direct scenes in chapels have no equivalent in the synagogue. A Jewish viewer will not walk into a foreign synagogue confused at the lack of figural murals. To point at biblical paintings depicting Jewish people and claim them as Jewish art for their content alone seems shallow and uninspired. Depictions of Christ, saints, and martyrs, work for Christianity because their exaltation and sacrifices are a key element to the goals of Christianity. This is not so in Judaism. Cultural aspects aside, focusing solely on the religious tenets, scholarship, learning and questioning are the goal; scenes from the Torah are meant to inspire thought and ponderance, not total exaltation. The question then becomes, how does one represent these tenets that are not so tangible? Chagall's paintings configure Jewish text into surreal image, reflecting the wonders, miracles, and acts of faith whose narratives reflect the pillars of religious teachings in Judaism. They go beyond straightforward representation, offering a Jewish perspective on these biblical scenes, one that does not present such scenes as empirical truth nor demand the viewer to exalt their figures. His depictions instead present the stories and figures as up for interpretation. Take his green-faced Moses as an example. It is a representation of a distinct scene but with an individual artistic liberty in the coloring that separates the scene from empirical truth and allows for room to question. Alas, one might begin to ask, have we found the Jewish art and artist here? Are Jewish people to take Chagall as their prize and chosen representative in the canon of modern art? 


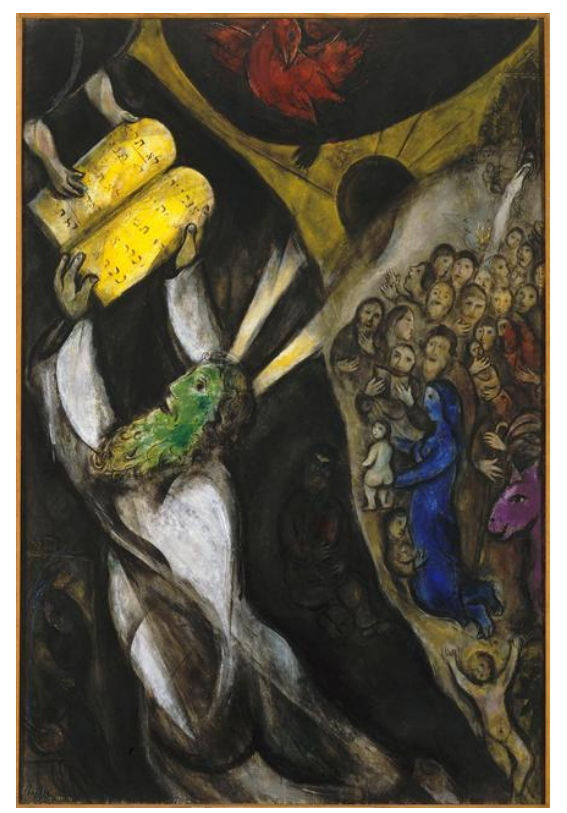

Figure 1. Marc Chagall, Moses Receiving the Tablets of the Law, 1952

Rosenberg isn't thoroughly convinced by Chagall's case, and makes reference to the grouping together of Chagall with his Jewish, Parisian neighbors, Amedeo Modigliani and Chaim Soutine, who together, not fitting into the Mediterranean or Nordic modes, find themselves in a ghetto of German art historian Werner Haftmann's making, simply by the fact of being Jewish. Haftmann was a non-Jew who lived through the Second World War in Germany and who would have been conditioned under such anti-Semitism, regardless of the actuality of his own sympathies, would be privy to repeating the same pattern of obvious identification, i.e. lumping the obvious Jews together. In much the same fashion that the Nazi's corralled Jewish people into segregated areas, these artist have been confined together on the basis of their Jewishness alone. But, as Rosenberg points out, beyond their Jewish identity, Haftmann does not make much argument in so far as the comparison of their styles of painting or in the overall look or intention of their works. When asking if these works are Jewish art, we must now move beyond thinking on the modern sensibility of what constitutes "art" in the distinction between craft or ceremony. If Rosenberg is not satisfied with these Jewish individuals as representatives of a Jewish art, one must turn away from contemplating the individual and ask: what constitutes a movement? What is the intention of the artists' works? Who else is in conversation with these works? What aesthetics are at play? Do they speak to a common truth or, possibly, a Jewish truth? This questioning and subsequent critical thought is necessary if Jewish art is to be liberated from its ghetto, that is, its strict 
classification based on the artist's identity category alone. And further, one must ask if identity can in fact be transferrable into work and how? If it can, is that permit enough to label the artwork by that identity?

Beginning to contemplate the possible "look" of Jewish art, assuming that there is one (or potentially many_ potentially so many Jewish art forms and "looks" exist that to extract them from the cloak of Jewish culture is to sift salt from sugar), Rosenberg detours into thoughts on the "look" of Jews:

"Similarly, many people deny the reality of Jewishness. They say, for instance, that there is no such thing as looking like a Jew; we know perfectly well, they say, that there are people who look like Jews who are not Jews. But if there are non-Jews who look like Jews, there must be such a thing as looking like a Jew. And if there is such a thing as looking like a Jew, does it not follow that the art Jews produce must also have a look of its own — that this art must look like Jewish art? In that case, there is a Jewish style — for in art the look is the thing."

If we then look at Jewish art through Rosenberg's comparative lens of Jewish ethnic presentation, Chagall and company could be akin to Nazi propaganda images of Jewish "looks": too easy to identify and offensively so. Of course, this elicits many troubling implications of fixing a Jewish physiognomy onto not only a person but to what they create, dangers that Rosenberg raises but avoids addressing directly. This is not, however, to comment negatively on Chagall as a representative of a Jewish perspective in modern art, but to say that there is some laziness in the lack of vigilance in looking beyond this one peculiar "look." The Jewish "look" extends beyond the stereotype, and has vast moments of subtlety and nuance, which Rosenberg does not mention. He does, however, introduce the figure of Werner Haftmann. However, a Jewish eye, which is trained to find like as a form of self-preservation, could pick out that nuance of the "look." For those peoples who are oppressed, and forced to be cautious in their interactions and the revealing of their identity, having a keen eye for like-people can be a matter of life or death. There are certain "looks" or mannerisms or even attitudes that are expressions of Jewish identity. This inter-communal coding is even more difficult to explain in words, and is more an intuition that comes from lifetimes of exposure and familiarization. In the same way, the Jewish eye searching for Jewish art, at least in Rosenberg's case, then turns to the New York Jews, the Newmans, Gottliebs, Lipschitz's and Epsteins: the Webers, the Steinbergs, and the 
Rothkos. Rosenberg claims these are the faces of American Art, however, this leaves no room for other identities for America is the conqueror of identity as all culture is helpless to the tide of the melting-pot's homogeneous waters of assimilation. But, suspend that disbelief and consider that these artists are not just American, but Jewish Americans, Jewish immigrants and their children. Their art falls into at least one category of Jewish art that is "art made by Jews," which begs the question, what else could be fulfilled that he would overlook? From the contemporary vantage point, one would understand the art made by these individuals not just as "American Art" but also, as part of the movement of "Abstract Expressionism," with Newman and Rothko as some of the movement's champions. Could this be a movement that qualifies a Jewish art in mid-century modernity? It is art made by Jews (albeit not entirely) who are in conversation with one another, sharing a common look, point of view, and intention. But can they portray Jewish subjects if they are abstract and non-representational?

In Annie Cohen-Solal's biography of Mark Rothko, Toward the Light in the Chapel, she presents an account of the artist which focuses on his Jewish culture and identity and how his evolution of style, leading to the color field paintings for which he is most well known, was influenced by that background (Cohen-Solal, Annie 2015). Cohen-Solal marks the beginning of Rothko's journey to abstraction with his grappling with surrealism. Rothko refers to surrealism as having "uncovered the glossary of the myth" and "established a congruity between the phantasmagoria of the unconscious and the objects of everyday life." Surrealism was born from the aftermath of the First World War. Its father, André Breton, a former Dadaist, brought with him the same air of nonsense and confusion of Dada's post-war commentary, but without the nihilism, aiming instead to find meaning in the nonsense and looking to the unconscious for truth. Rothko's exploration with surrealism is dated as being between 1944-1947, which would situate it as a mirror to the origins of surrealism, using the movement to confront the state of the world at the end of a war. As Grace Glueck presents in her 1981 New York Times article, "Art: Rothko as Surrealist in his Pre-Abstract Years," (Glueck, Grace 1981) this period of his work sees the emergence of some of the forms that he will later repeat in his color-field pieces when he dedicates himself to complete abstraction. In his 1944 painting, Poised Elements (fig. 2), Rothko situates a cluster of surreal forms atop three horizon bands of color which, when isolated, assume the embryonic status of the hazy, "mist-edged" blocks of color of Rothko's later works. In his work from the same year, Slow Swirl at the Edge of the Sea (fig. 3), we find an early 
exercise in scale, as the piece measures $190.5 \times 215.9 \mathrm{~cm}$ total, large enough to envelop the viewer. These are the elements that follow him into abstraction.

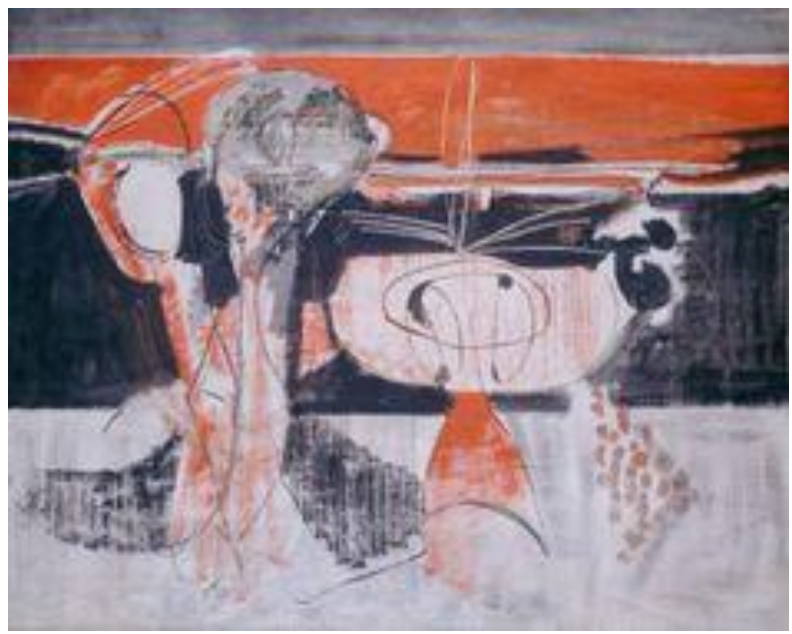

Figure 2. Mark Rothko, Poised Elements, 1944

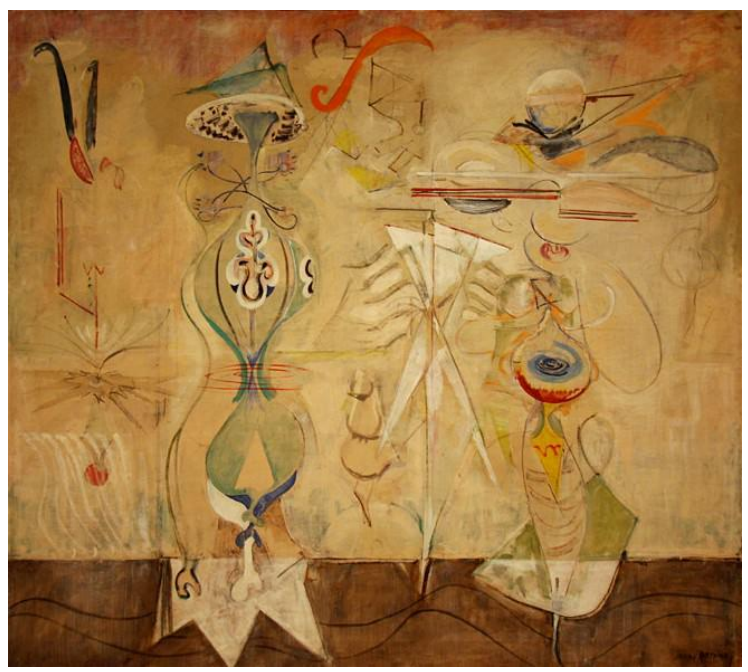

Figure 3. Mark Rothko, Slow Swirl at the Edge of the Sea, 1944

An important element of Rothko's color-field works, which took shape most solidly in the 1950s and continued for the rest of his life, is of course color (Rothko,Mark 2006). These works are typically untitled, numbered, or listed with the colors interacting on the canvas, allowing no restriction in the viewer's interpretation, meditation, and overall journey of discovery in the experience of one of the artist's epically sized works. As he progresses with this style, the paintings get larger and larger, growing in the scale until they become large masses of color taller than any person in the gallery or museum. If the canvas can easily consume the viewer's body, there lies a power dynamic in which the audience is overcome by the art. This could be 
anxiety inducing, or it could be transcendent. In another interaction, the large canvas presents itself as a portal, a trap door, and an escape. Standing in front of one of these more monstrously proportioned pieces, where the field of colors is all-encompassing to your vision, the world is able to melt away in the fringes. This offers an opportunity for meditation and even prayer. The viewer's experience mirrors the introspection of the artist while creating.

The movement of Abstract Expressionism is itself a response to the Second World War as well, and not all Abstract Expressionists or those who dealt with abstraction at this time were Jewish. We can perhaps consider these individuals to be the non-Jews who "look Jewish," meaning that having the "look" of Abstract Expressionism, does not necessarily denote a Jewish art or artist, but that the presence of non-Jews in that arena also does not negate the association of Jews and abstraction. Abstraction is a broad aesthetic that can refer to the distortion of figures, non-figural depiction, and the use of non-local color among other techniques. These methods are like "codes" which can indicate that something is abstract expressionism. This is parallel to the concept of the "Jewish look", where elements of an individual's looks can code someone as ethnically Jewish. Neither of these sets of codes are absolute, as someone who is Jewish coded might be of a different heritage. However, they do not discount the validity of those codes being applied to Jewishness, just as non-Jewish artists using codes of abstraction and abstract expressionism does not cancel the association between those aesthetics and Jewish aesthetics. A difference in the response to the Second World War between Jewish and non-Jewish Americans lies in their relation to the Holocaust. Mourning is a theme whose presence is not uncommon in the work of Abstract Expressionism. Barnett Newman, another Jewish Abstract Expressionist who developed his own color field painting style alongside Rothko demonstrates a deep mourning in his 1949 piece Abraham (fig. 4), which makes reference to the specific death of Newman's father, but can also be understood as a communal mourning. Rothko himself was Ashkenazi and it is impossible to discuss the effect of the war on American abstraction without also being aware of the effects of the Shoah. Mark Godfrey asserts in his book, Abstraction and the Holocaust, that he does not "believe that in any extant work Mark Rothko attempted to address the Holocaust, but all of his work was made in its shadow." This can be applied to most other Jewish artists not tackling the Shoah necessarily directly, but its impact presenting itself in the very foundation of their work (Godfrey,Mark 2013). Ulrike Gehring speaks on this issue citing that: 
"For Mark Rothko, modernity first began to take shape in 1941, when Hitler's plans for the Jews were becoming known in America, and the Jewish artist of Russian descent banished figural references from his imaginal world. The subject, conjured by artists for more than two thousand years, lost not only meaning but also, in Rothko's case, its iconographic existence. “(Picard,Jacques et al. 2016)

Some might see Rothko's abstractions and non-figural depictions as a lack, an absence, and a void yearning to be filled. Along with his horizons of color, other forms Rothko explores are frames within the canvas. Many of the paintings, one being his, Red on Maroon (fig. 5), which explore this configuration, are also explorations of the color red. These empty frames, if one is inclined to extrapolate that image from them, as with all abstract works the image is merely implied and not a certainty, depict an emptiness which could be read as the missing forms of those who were murdered in the camps and a solidarity in mourning. It could even be the lack of a G-d who would turn an eye away from their people and allow for such a horror. But, this is the pessimists view. In as many ways as these works could be seen for their lack, they can also be seen for their sublimity and all-encompassing presence.

Figure 4. Barnett Newman, Abraham, 1949 


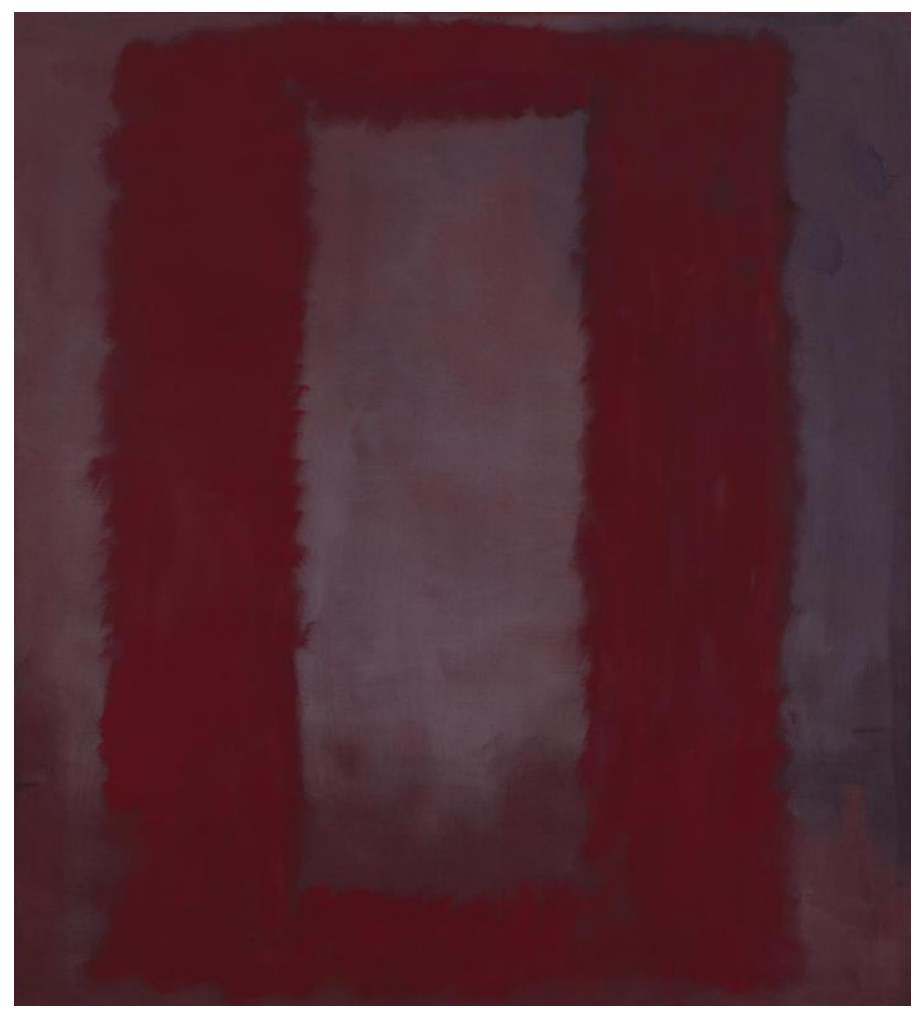

Figure 5. Mark Rothko, Red on Maroon, 1959, Tate Modern

Jewish American literary and social critic Irving Howe once said in reference to modern Jewish artists, "To become an avant-garde painter meant to become an avant-garde Jew: a figure apart, perhaps torn away, undertaking a journey of dispersion more radical than that of other Jews." Applying this to the question of Rothko and what one could consider a Jewish motif in abstract expressionism, means to consider Judaism in the abstract - to turn away from physical characteristics of the faith, as we see in Chagall's work, which for all its departures from typical biblical depiction, still adheres to figural form. While Rothko asserted that his works did have subjects, those subjects are not in the form of figures. In Rothko's writing he states, "To say, therefore, that abstract painting does not posses a subject matter, which, as we have already said, is some kind of reference to our experience, would be the statement of an impossibility." He posits the subject as an intangible reality; an owned experience. This wording could indicate a singular event, or the lived experiences of communal identity. He claims they "appeal to our sense of the familiar" (Rothko,Mark 2004). Because his paintings work in non-figural depiction and total abstraction, they speak to multiple interpretations simultaneously: the formlessness, omnipresence of a G-d, to an uncertainty, and a process of questioning. In this way they are 
Judaica, or Rabbis; they are the Yeshiva, creating spaces for the ultimate questions, the curiosities that are boundless and open-ended. They speak to the formlessness of thought itself, the intangibility of prayer. This is a product of abstraction. Rothko comments, "the fact that lots of people break down and cry when confronted with my pictures shows that I communicate those basic human emotions... The people who weep before my pictures are having the same religious experience I had when I painted them." This doesn't indicate definitively that Rothko's works are calling out to G-d or praise G-d, only that the possibility exists in their abstraction. Rothko intended for a spiritual, emotional connection to occur through his pictures. In this way I believe they represent a Jewish mode, and complete the requirements set forth by Rosenberg to be "Jewish art."

Harold Rosenberg doesn't claim that Judaism is absent completely from this art but he wouldn't call it Jewish art either. Rather, Rosenberg considers it art concerned with identity. In the conclusion of his article he states:

"This work (modern art produced by Jewish-American artists) inspired by the will to identity has constituted a new art by Jews which, though not a Jewish art, is a profound Jewish expression, at the same time that it is loaded with meaning for all people of this era. To be engaged with the aesthetics of self has liberated the Jew as artist by eliminating his need to ask himself whether a Jewish art exists or can exist."

This aesthetics of self is referential to what Rosenberg considers emblematic of modern art: the concerns of self-expression and internal contemplation. Conclusively, he believes there is no Jewish "art", but rather a new movement driven with identity at the helm, and the Jewish "look" we might recognize is a product of the Jewish artist's introspection of the self. Rosenberg's core perspective, which informs his whole argument, is that Jewishness informs identity and identity informs "the self," but that they are not all three equivalent. Therefore, a Jewish artist can engage with the self, and not necessarily be engaging with Judaism. In an age so close to an attempted genocide where Jews were being hunted down for their Jewish-ness, where it meant death, that categorization would feel like shackles. It would be liberating to be able to claim nationalism first as Rosenberg does when he conditions abstract expressionism as "American art," putting culturalism second and optionally to nationalism by claiming Jewish identity as only informing the self. But, now, almost eighty years since the Nazi's invaded France and some fifty years after the publication of Rosenberg's words in Commentary Magazine, it is time to reconsider these 
sentiments. Where diversity is celebrated and assimilation is critiqued, Rosenberg's insistence that this art is not Jewish but American acts as a form of erasure, almost parallel to assimilation itself. Is it not the time to reconsider the question "Is there a Jewish art?" and to redefine what the art world considers a Jewish aesthetic?

To conclude, let's consider the Jewish laws of visual representation in the second commandment, which states, "Thou shalt not make unto thee any graven image, or any likeness of any thing that is in heaven above, or that is in the earth beneath, or that is in the water under the earth. Thou shalt not bow down thyself to them nor serve them." Rosenberg refers to this as the "manifesto of Jewish art" and that in regards to the anti-art movements of the twentieth century, "it could be asserted that Jewish art has always existed in not existing." Analyzing Rothko's color-field painting through the commandment, by not depicting the likeness of any earthly creation in his paintings, he is in compliance with that law. If it does not denote a Jewish art directly, is it not proof of the possibility of what could be a fundamentally Jewish aesthetic? If non-figural depiction is considered a way of expressing and honoring a Jewish aesthetic, is not abstraction itself the ultimate Jewish aesthetic? If it is argued that the Jewishness of Abstract Expressionism goes beyond "the look" of it and claims the aesthetic, the guiding and underlying principals of abstraction, then art produced through this movement is Jewish art, not necessarily in the style of the painting, or necessarily the identity of the artist, but in the essence of its principals: its questioning of reality, its presentation of the malleability of truth, and its sublime nature and connection with spiritual experience.

\section{Acknowledgements}

Thank you to Dr. Rachel Silveri, without whom this paper would not exist.

\section{References}

Cohen-Solal, A. (2015). Mark rothko: Toward the light in chapel.

Glueck, G. (1981). Art: Rothko as surrealist in his pre-abstract years. The New York Times.

Mark Godfrey (2013). Gale. Abstraction and the Holocaust. Yale University Press.

Picard, J., Revel, J., Steinberg, M. P., Zertal, I., \& Flem, L. (2016). Makers of jewish modernity : Thinkers, artists, leaders, and the world they made Princeton, New Jersey : Princeton University Press, 2016]. 
Rosenburg, H. (1966). Is there a Jewish art? Commentary Magazine.

Rothko, M., \& López-Remiro, M. (2006). Writings on art New Haven : Yale University Press, c2006.

Rothko, M., \& Rothko, C. (2004). The artist's reality : Philosophies of art New Haven : Yale University Press, c2004. 